\title{
Prevalence and Antifungal Susceptibility Pattern of Yeast Species Isolated from the Diverse Samples at Dr Lal Path Labs, Delhi, India
}

Singh $\mathrm{P}^{1}$, Malik $\mathrm{S}^{2 *}$ and Lal $\mathrm{V}^{2}$

${ }^{1}$ Department of Microbiology and Serology, Research Scientist, Dr Lal Path Labs, National Reference Laboratory, Delhi, India

${ }^{2}$ Department of Microbiology and Serology, National Head, Dr Lal Path Labs, National Reference Laboratory, Delhi, India

\section{Research Article}

Volume 3 Issue 1

Received Date: March 13, 2020

Published Date: March 31, 2020

DOI: $10.23880 /$ oajmms-16000120

*Corresponding author: Dr Shalabh Malik, Department of Microbiology and Serology, National Head, Dr Lal Path Labs, National Reference Laboratory, Rohini, Delhi, E-mail: Shalabh.malik@lalpathlabs.com

\section{Abstract}

Objective: This study aimed at determining the prevalence and antifungal susceptibility pattern of Candida albicans and Nonalbicans Candida species from various clinical specimens tested in microbiology department of $\mathrm{Dr}$ Lal Path Labs, Delhi.

Materials and Methods: This retrospective study conducted on 2240 samples, tested between January2019 to July 2019 , performed at Microbiology department of Dr. Lal Path Labs. Yeast species were cultured by Conventional (culture) and identified by MALDI-TOF which followed by antifungal susceptibility testing was done using Vitek 2 YST YS07 card.

Results: 737 Candida isolates of 16 diverse species were isolated from 2240 various clinical specimens. Candida albicans (54.9\%) was predominant followed by C. tropicalis (14.7\%), C. glabrata (11.7\%), C. parapsilosis (4.3\%), and C krusei (3.5\%). Uncommon Candida species such as Candida auris, Rhodoturula mucilaginosa, Trichosporon asahii, Malassezia pachydermatitis, Kodameae ohmeri were also isolated. The most predominant age group infected with yeast isolates were elderly adults $>=60$ years of age which constituted $45.5 \%$ of the fungal culture positive cases. Alarming antifungal resistance noticed in Nonalbicans Candida species as compared to Candida albicans. In the present study, Candida albicans showed high resistance to newest generation Azole, Voriconazole (42.2\%) whereas the burden of Echinocandin resistance is still alarming in Nonalbicans Candida infections.

Conclusion: The fungal pathogens has changed over a period with new species emerging as well as old species increasing become more virulent and resistant to primary antifungal drugs. We should be concern about the national emergence of resistance among varying Candida species obtained in diverse clinical situations.

Keywords: BAL (Broncho Alveolar Lavage); Echinocandins; Polyenes; Azoles; Non-albicans Candida

\section{Introduction}

Candida as is incidence has increased over the last decades, which includes the fungal infections in human beings by various Candida species causing superficial infections involving skin, hair and nail and systemic infections among the uncompromised and severe immune compromised patients such as cancers patients, undergoing organ transplants, HIV infected individuals. Although Candida albicans remains the most common Candida species and predominantly reported, 
whereas Candida tropicalis, Candida glabrata, Candida parapsilosis and Candida krusei is emerging yeast among Non albicans Candida species and approximately $90 \%$ of invasive infections are caused by these few species. The morbidity and mortality caused by Non-albicans Candida (NAC) species are increasing [1,2].

Studies regarding the drug susceptibilities profile vary among Candida albicans, Non-albicans carried out worldwide and apart from their reduced susceptibility to Azole and Echinocandins here; we briefly discussed our findings among pathogenic species of yeast and their antifungal susceptibility patterns [3-5].

\section{Materials and Methods}

This retrospective study conducted on 2240 samples, tested between January to July 2019, performed at Microbiology department of Dr Lal Path Labs.

The samples subjected to direct microscopy-using KOH wet mount, and India ink preparations depending on the type of specimen. Fungal culture done on SDA agar, with chloramphenicol $(16 \mu \mathrm{g} / \mathrm{mL})$ and with cycloheximide $(0.3 \mu \mathrm{g} /$ $\mathrm{mL})$ plus chloramphenicol $(16 \mu \mathrm{g} / \mathrm{mL})$, Specimens were cultured in duplicate; one set of inoculated slants incubated at $25^{\circ} \mathrm{C}$ and the other incubated at $37^{\circ} \mathrm{C}$, and they were examined every day for growth up to 4 weeks before discarding as negative. Fungal growth as identified by colony morphology and use of more advanced and standardized methods, such as MALDI TOF-MS (Bruker, Daltonics) were included in this study. VITEK-2 (Biomerieux) system used for the antifungal susceptibility testing of isolates from the pure culture of isolated colonies of the Candida species on CHROM agar Candida, and antifungal susceptibility was carried out on YS07 cards respectively. The results interpreted according to CLSI criteria M60-1edition 2017 [6].

Statistical analysis: For the evaluation of the Data analysis, Myla statistical program (bioMerieux, India, Pvt. Ltd) used.

\section{Results}

During the period of January 2019 to July 2019, A total number of 737(32.9\%) Candida species isolated from 2240 various clinical specimens like BAL (42.9\%), sputum (25.1\%) endotracheal secretion $(3.7 \%)$, urine $(6.9 \%)$, pus (4.2\%), nails (4.1\%), tissue (3.1\%), high vaginal swab (2.8\%), sterile body fluids $(2.8 \%)$, blood $(2.3 \%)$, skin $(1.2 \%)$, stool $(0.2 \%)$ respectively (Table 1$)$. Overall, 737 positive isolates of Candida species were collected from 426 males and 311 females and the age range of our study participants was 0 to 95 years. Ninety-two per cent of the study population belonged to the age group of 21->70 years which is the major population group (Figure 1).

\begin{tabular}{|c|c|c|c|c|c|c|c|c|c|c|c|c|}
\hline Specimen & Sputum & BAL & $\begin{array}{c}\text { Endotracheal } \\
\text { tip }\end{array}$ & Pus & Tissue & $\begin{array}{c}\text { Sterile } \\
\text { Body fluids }\end{array}$ & Nail & Skin & Urine & Stool & $\begin{array}{c}\text { Genital } \\
\text { Vaginal }\end{array}$ & Blood \\
\hline $\begin{array}{c}\text { Yeast spp. } \\
\text { n=737 }\end{array}$ & 185 & 31.6 & 27 & 31 & 23 & 21 & 30 & 9 & 51 & 2 & 21 & 17 \\
\hline $\begin{array}{c}\text { \% of yeast } \\
\text { spp. }\end{array}$ & 25.1 & 42.9 & 3.7 & 4.2 & 3.1 & 2.8 & 4.1 & 1.2 & 6.9 & 0.2 & 2.8 & 2.3 \\
\hline
\end{tabular}

Table 1: Prevalence of total fungal (Yeast species) isolates in different samples during January to July 2019.

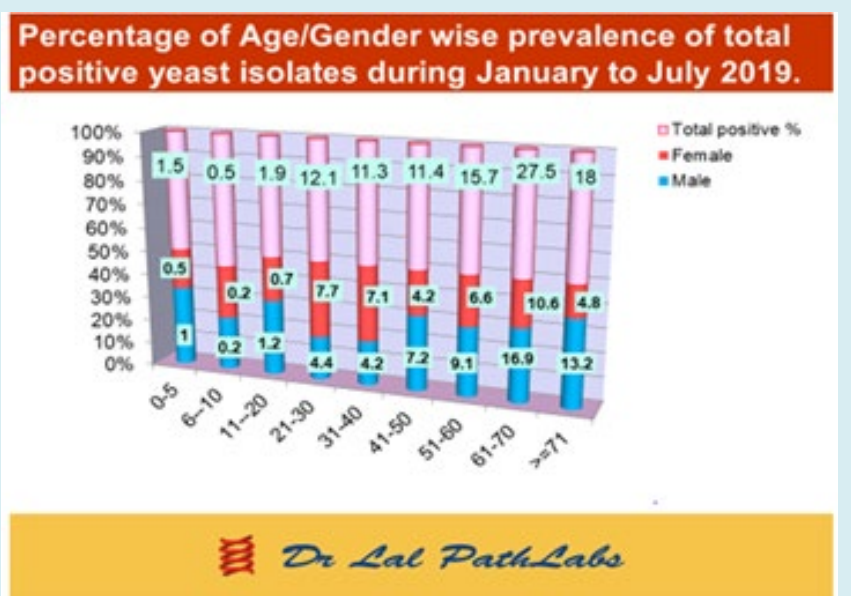

Figure 1: Age and gender wise prevalence of positive fungal (yeast species) isolates from different type of samples. 
Most of our specimens collected from Delhi and the neighbouring states of North India. Total 16 Candida species identified from these 12 different clinical samples. Among them, Candida albicans (54.9\%), C. tropicalis (14.7\%), C. glabrata (11.7\%), C. parapsilosis (4.3\%), and C. krusei (3.5\%), C. kefyr $(2.3 \%)$ were the six predominant candida species. Numerous uncommon Candida species such as Candida auris, Candida cantenulata, Candida metapsilosis, Candida lusitaniae, Candida haemulonii, Rhodoturula mucilaginosa, Trichosporon asahii, Malassezia pachydermatitis, Cryptococcus magnus,
Kodameae ohmeri were also isolated in this study (Figure 2).

Over the 6 month period, Candida albicans 405/737 (54.9\%) and Non-albicans Candida constituted 332/737 (45.1\%) of the total isolates. In this study, the Candida species isolated from the BAL specimen were predominant (Table 1,3). 45.1\% of Non-albicans candida species including C. tropicalis, C. glabrata, C. parapsilosis, C. krusei and C. kefyr accounted $36.5 \%$ whereas the other ten non-albicans Candida accounted for $8.6 \%$ (Figure 2).

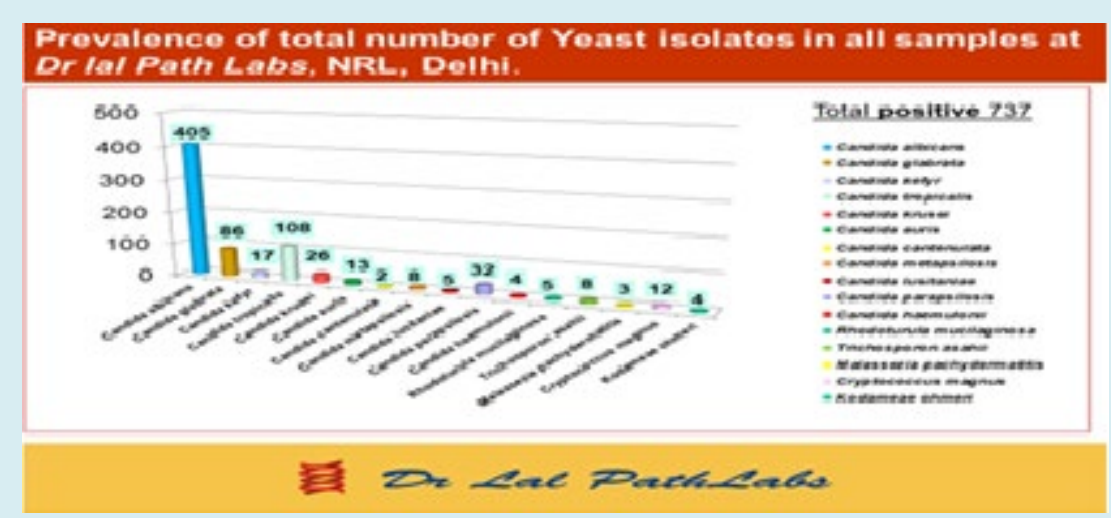

Figure 2: Total number and Percentage wise prevalence of positive fungal (yeast species) isolates from different type of samples.

In this study Candida albicans were most frequently isolated from BAL, Sputum, Endotracheal tip (83.4\%) followed by Urine, Pus, Nail specimen respectively (Table 2).

Among the most dominant Non-albicans Candida species, Candida tropicalis accounted for (66.7\%) Candida glabrata (55.8\%) and C. parapsilosis (56.3\%) of isolates obtained from respiratory tract samples and rest Candida species obtained from other specimens. Of the later other uncommon nonalbicans C. metapsilosis species (87.5\%), Trichosporon asahii (55.5\%), and Cryptococcus magnus (66.7\%), obtained from other specimens whereas Rhodoturula mucilaginosa and Malassezia pachydermatitis isolated only from skin and tissue (Table 2). Of the 737 Candida cases reported earlier $13(1.8 \%)$ were due to $C$. auris. The majority of these $C$. auris cases were isolated from elder adults $10(>60 \mathrm{yrs})$ and three were from (0-2yrs) age. In Delhi Candida auris is also, an emerging infection reported and were isolated from BAL, sputum respectively. In this study four isolates of Kodameae ohmeri $(0.5 \%)$ infections were isolated from sputum, BAL, urine in patients of elder $(>60)$ age groups (Table 2$)$.

\begin{tabular}{|c|c|c|c|c|c|c|c|c|c|c|}
\hline Yeast Species & $\begin{array}{c}\text { Sputum } \\
\mathbf{N}(\%)\end{array}$ & $\begin{array}{c}\text { Bal N } \\
\mathbf{( \% )}\end{array}$ & $\begin{array}{c}\text { Blood } \\
\mathbf{N}(\%)\end{array}$ & $\begin{array}{c}\text { Body } \\
\text { fluids } \\
\mathbf{N}(\%)\end{array}$ & $\begin{array}{c}\text { Pus N } \\
\mathbf{( \% )}\end{array}$ & $\begin{array}{c}\text { Tissue } \\
\mathbf{N}(\%)\end{array}$ & $\begin{array}{c}\text { Nail \& } \\
\text { Skin }\end{array}$ & $\begin{array}{c}\text { Urine } \\
\mathbf{N}(\%)\end{array}$ & $\begin{array}{c}\text { Genital } \\
\text { Vaginal }\end{array}$ & $\begin{array}{c}\text { Endotracheal } \\
\text { N (\%) }\end{array}$ \\
\hline $\begin{array}{c}\text { Candida albicans } \\
(n=405)\end{array}$ & $\begin{array}{c}126 \\
(31.1)\end{array}$ & $\begin{array}{c}201 \\
(49.6)\end{array}$ & $\begin{array}{c}5 \\
(1.2)\end{array}$ & $7(1.7)$ & $13(3.2)$ & $6(1.5)$ & $9(2.3)$ & $19(4.7)$ & $8(1.9)$ & $11(2.7)$ \\
\hline $\begin{array}{c}\text { Candida glabrata } \\
(n=86)\end{array}$ & $18(20.9)$ & $26(30.2)$ & $\begin{array}{c}2 \\
(2.3)\end{array}$ & $5(5.8)$ & $3(3.5)$ & $2(2.3)$ & $9(10.5$ & $\begin{array}{c}11 \\
(12.8)\end{array}$ & $6(6.9)$ & $4(4.7)$ \\
\hline $\begin{array}{c}\text { Candida kefyr } \\
(n=17)\end{array}$ & $4(23.5)$ & $7(41.2)$ & $1(5.9)$ & -- & --- & --- & --- & $4(23.5)$ & --- & $1(5.9)$ \\
\hline $\begin{array}{c}\text { Candida tropicalis } \\
(n=108)\end{array}$ & $22(20.4)$ & $45(41.7)$ & $\begin{array}{c}5 \\
(4.6)\end{array}$ & $8(7.4)$ & $5(4.6)$ & $1(0.9)$ & $4(3.7)$ & $9(8.3)$ & $4(3.7)$ & $5(4.6)$ \\
\hline
\end{tabular}




\section{Open Access Journal of Mycology \& Mycological Sciences}

\begin{tabular}{|c|c|c|c|c|c|c|c|c|c|c|}
\hline $\begin{array}{c}\text { Candida krusei } \\
(n=26)\end{array}$ & 5 (19.2) & $11(42.3)$ & $\begin{array}{c}2 \\
(7.7)\end{array}$ & -- & $2(7.7)$ & --- & $2(7.7)$ & $1(3.8)$ & $1(3.8)$ & $2(7.7)$ \\
\hline $\begin{array}{c}\text { Candida auris } \\
(n=13)\end{array}$ & $3(23.1)$ & 7 (53.8) & --- & $1(7.7)$ & $1(7.7)$ & --- & --- & --- & --- & $1(7.7)$ \\
\hline $\begin{array}{c}\text { Candida } \\
\text { cantenulata }(n=2)\end{array}$ & $1(50)$ & -- & ---- & -- & $1(50)$ & --- & --- & --- & -- & -- \\
\hline \multirow{2}{*}{$\begin{array}{c}\text { Candida } \\
\text { metapsilosis }(n=8)\end{array}$} & \multirow{2}{*}{---} & \multirow{2}{*}{$1(12.5)$} & 1 & 1 & \multirow{2}{*}{$1(12.5)$} & \multirow{2}{*}{$2(25)$} & \multirow{2}{*}{---} & \multirow{2}{*}{$2(25)$} & \multirow{2}{*}{---} & \multirow{2}{*}{---} \\
\hline & & & -12.5 & -12.5 & & & & & & \\
\hline $\begin{array}{c}\text { Candida } \\
\text { lusitaniae }(n=5)\end{array}$ & $1(20)$ & $3(60)$ & ---- & --- & --- & ---- & --- & $1(20)$ & --- & ----- \\
\hline $\begin{array}{c}\text { Candida } \\
\text { parapsilosis } \\
(n=32)\end{array}$ & $2(6.3)$ & $8(25)$ & $\begin{array}{c}1 \\
(3.1)\end{array}$ & --- & 5 (15.6) & $6(18.8)$ & --- & $1(3.1)$ & $1(3.1)$ & $8(25)$ \\
\hline $\begin{array}{c}\text { Candida } \\
\text { haemulonii }(n=4)\end{array}$ & --- & $2(50)$ & --- & $1(25)$ & $1(25)$ & ---- & --- & ---- & ----- & ------ \\
\hline $\begin{array}{c}\text { Rhodoturula } \\
\text { mucilaginosa } \\
(n=5)\end{array}$ & --- & --- & --- & --- & --- & $3(60)$ & $2(40)$ & --- & --- & ---- \\
\hline $\begin{array}{c}\text { Trichosporon } \\
\text { asahii }(n=9)\end{array}$ & $2(22.2)$ & $2(22.2)$ & --- & ---- & ---- & 1 (11.1) & $2(22.2)$ & $2(22.2)$ & ---- & ---- \\
\hline $\begin{array}{c}\text { Malassezia } \\
\text { pachydermatitis } \\
(n=3)\end{array}$ & --- & --- & --- & ---- & ---- & $1(33.3)$ & $2(66.7)$ & --- & --- & ---- \\
\hline $\begin{array}{l}\text { Cryptococcus } \\
\text { magnus }(n=12)\end{array}$ & --- & $4(33.3)$ & --- & --- & -- & $2(16.7)$ & $2(16.7)$ & $1(8.3)$ & $1(8.3)$ & $2(16.7)$ \\
\hline $\begin{array}{c}\text { Kodameae ohmeri } \\
(n=4)\end{array}$ & $1(25)$ & $2(50)$ & --- & --- & --- & --- & --- & $1(25)$ & --- & ----- \\
\hline
\end{tabular}

Table 2: Positive percentage of different type of yeast species in different type of samples during January to July 2019.

This study has been noted that Micafungin, Flucytosine and Amphotericin B were recorded highly sensitive to most of the yeast isolates while Azole antifungal have long provided effective treatment for Candida species so development of high level Azole resistance is a problem of critical importance in clinical settings in North India (Figure 3).

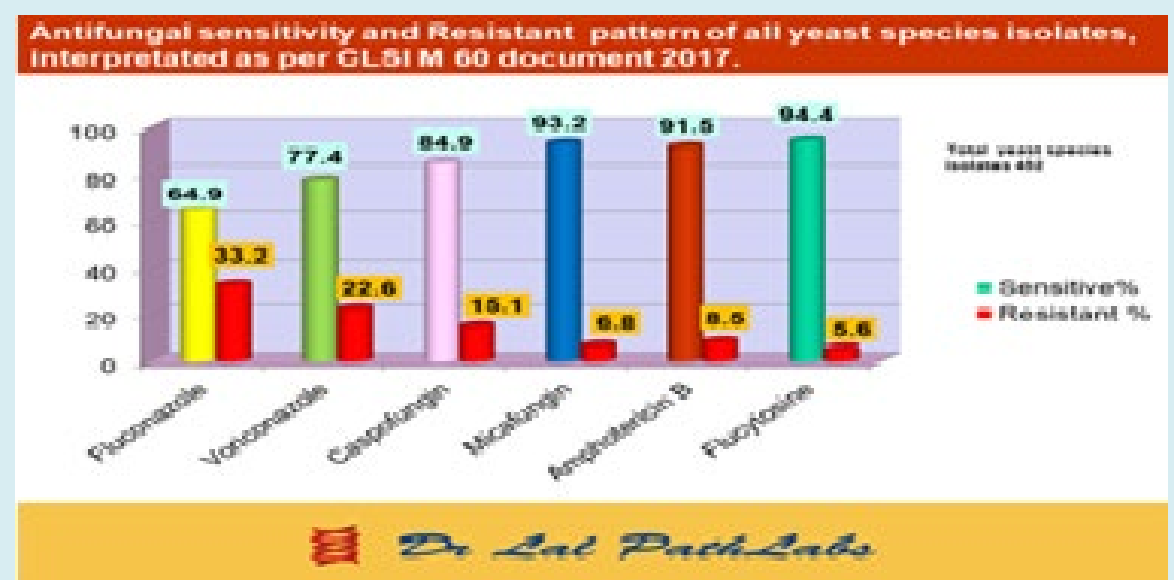

Figure 3: Total percentage of Cumulative interpretation of Antifungal Sensitivity/Resistant patterns of all Candida species during January to July 2019. 
In addition, this study describes for the cumulative MIC interpretation of antifungal sensitivity patterns among most dominant Candida species with help of Myla statistical analysis (Biomerieux, India) which causes complicated invasive infection such as Candida albicans shown highly resistant to Voriconazole (42.2\%) and Fluconazole (32.8\%) respectively. Voriconazole activity $\left(\mathrm{MIC}_{50 / 90<0.12 / 4}\right)$ against Candida albicans demonstrated that $50 \%$ of isolate were within $0.12 \mu \mathrm{g} / \mathrm{ml} \mathrm{MIC}$ and $90 \%$ isolates were within $4 \mu \mathrm{g} /$ $\mathrm{ml}$. Total 224 (55.5\%) Candida albicans isolates were tested against all antifungal, 98.9\% Candida albicans sensitive to Caspofungin was having $\mathrm{MIC}_{50 / 90}(<=0.12 / 0.25 \mu \mathrm{g} / \mathrm{ml})$ and $98.1 \%$ of Flucytosine sensitive isolates having MIC ${ }_{50 / 90}(<=1 / 2 \mu \mathrm{g} / \mathrm{ml})$ were noted (Table 3$)$. Out of 86 tested isolates of Candida tropicalis all antifungal drugs having ${ }_{50 / 90}$ (<=0.12to $1 \mu \mathrm{g} / \mathrm{ml}$ ) only $3 \%$ isolates resistant to Voriconazole, Caspofungin and Micafungin. Candida krusei were recorded decreased susceptibilities to Flucytosine (MIC at which $50 \%$ and $90 \%$ of isolates were inhibited $\left(\mathrm{MIC}_{50} \& \mathrm{MIC}_{90}\right)$, $8 \mu \mathrm{g} / \mathrm{ml}$ ) and Fluconazole activity $\left(\mathrm{MIC}_{50 / 90} 8 / 8 \mu \mathrm{g} / \mathrm{ml}\right)$ were demonstrated that all isolates were resistant to these drugs (Table 3). Second highest resistance recorded (25\%) of all drugs except Flucytosine in Candida parapsilosis. Most species of non-albicans Candida recorded resistant to Caspofungin except Candida kefyr. Nearly all the isolates of Candida species had $100 \%$ sensitive for Flucytosine, the notable exception being Candida krusei where 100\% isolates demonstrated resistant in Delhi. The distribution of Antifungal drugs MIC values against sensitivity patterns of Candida species followed in (Table 3).

\begin{tabular}{|c|c|c|c|c|c|c|c|}
\hline \multirow[b]{2}{*}{ Antifungal } & \multirow[b]{2}{*}{$\begin{array}{r}\text { MIC }(\mu \mathrm{g} / \mathrm{ml}) / \\
\text { Cumulative\% }\end{array}$} & \multicolumn{6}{|c|}{ Yeast Species } \\
\hline & & $\begin{array}{l}\text { Candida } \\
\text { albicans } \\
(\mathrm{n}=224)\end{array}$ & $\begin{array}{l}\text { Candida } \\
\text { Tropicalis } \\
(\mathrm{n}=86)\end{array}$ & $\begin{array}{c}\text { Candida } \\
\text { Glabrata } \\
(\mathrm{n}=60)\end{array}$ & $\begin{array}{c}\text { Candida } \\
\text { Krusei } \\
(\mathrm{n}=25)\end{array}$ & $\begin{array}{c}\text { Candida } \\
\text { Kefyr } \\
(\mathrm{n}=16)\end{array}$ & $\begin{array}{c}\text { Candida } \\
\text { Parapsilosis } \\
(\mathrm{n}=31)\end{array}$ \\
\hline \multirow{2}{*}{ Fluconazole } & MIC50 /MIC90 & 8-Jan & 2-Jan & --- & 0 & $0.5 / 2$ & $<=0.5 / 8$ \\
\hline & $\% \mathrm{~S}$ & 67.2 & 90 & --- & 0 & 100 & 75 \\
\hline \multirow[t]{2}{*}{ Voriconazole } & MIC50 /MIC90 & $<=0.12 / 4$ & $<=0.12 / 0.12$ & ---- & $\begin{array}{l}<=0.12 / \\
<=0.12\end{array}$ & 0.125 & $<=0.12 / 8$ \\
\hline & $\% \mathrm{~S}$ & 57.8 & 97 & ----- & 100 & 100 & 75 \\
\hline \multirow{2}{*}{ Caspofungin } & MIC50 /MIC90 & $<=0.12 / 0.25$ & $<=0.12 / 0.25$ & $<=0.12 / 0.25$ & $0.5 / 0.5$ & 0.125 & $0.5 / 8$ \\
\hline & $\% \mathrm{~S}$ & 98.9 & 97 & 50 & 42.9 & 100 & 75 \\
\hline \multirow[t]{2}{*}{ Micafungin } & MIC50 /MIC90 & $<=0.06 / 0.12$ & $<=0.06 / 0.06$ & $<=0.06 / 0.06$ & $\begin{array}{l}<=0.12 / \\
<=0.12\end{array}$ & 0.125 & 8-Jan \\
\hline & $\% \mathrm{~S}$ & 97.2 & 97 & 93.8 & 100 & 100 & 75 \\
\hline \multirow{2}{*}{ Amphotericin B } & MIC50 /MIC90 & $0.5 / 4$ & $<=0.25 / 0.5$ & $<=0.25 / 0.5$ & $0.5 / 1$ & 0.25 & $0.5 / 2$ \\
\hline & $\% \mathrm{~S}$ & 89.5 & 100 & 100 & 92.9 & 100 & 75 \\
\hline \multirow{2}{*}{ Flucytosine } & MIC50 /MIC90 & $<=1 / 2$ & $<=1 / 8$ & 0.5 & $<=8 / 8$ & $<=1 / 2$ & 1 \\
\hline & $\% \mathrm{~S}$ & 98.1 & 100 & 100 & 0 & 100 & 100 \\
\hline
\end{tabular}

Table 3: Percentage of Cumulative MIC interpretation and antifungal activity against most predominant yeast species from all age groups during January to July 2019.

\section{Discussion}

Among the Candida species, Candida albicans ranks first in incidence in our study followed by Non-albicans strains such as Candida tropicalis, Candida glabrata our findings were agreement with these western studies [2,7-9]. Whilst in the Indian settings which showed that Candida tropicalis was the most commonly isolated agent causing $30-60 \%$ of the cases $[1,10,11]$.

It is notable that geographically distribution of Candida species in Asian and Western countries were not similar
$[1,9,12,13]$. Various studies conducted at different part of India have found a higher incidence of Candidiasis due to Non-albicans Candida, with the isolation rate ranging from 40-70\%, Non-albicans Candida caused about 45\% cases in our study. Candida tropicalis and Candida glabrata has become predominant Non-albicans Candida species causing infection in our findings and it prevalence varies across geographic region and other previous studies by worldwide were concords with this study $[1,2,7,12,14,15]$.

Several classes of compounds that is Polyenes, Azoles, Echinocandins and Nucleoside analog are use with sensitivity 


\section{Open Access Journal of Mycology \& Mycological Sciences}

of Candida species. The most common prescribed antifungal Azole have long provided effective treatment for Candida species while development of high level Azole resistance is a problem of critical importance in clinical settings, therefore this research has focused on investigating its virulence. Fluconazole resistance increasing is worrisome about the therapy for Candida albicans and Non-albicans Candida infection [16].

In this study, Candida albicans were shown unusual high level of resistant to newest generation azole Voriconazole $(42.2 \%)$ in comparision to first line antifungal drugs Fluconazole $(32.8 \%)$ similar observation was also reported by previous study $[7,12]$. However other antifungal drugs reported sensitive our results are in agreement with the previously published study [11].

Of the interest in emergence of drug resistant Candida glabrata in many countries which has been associated with longer hospital stay and high attributable death have been associated with delayed initiation of appropriate antifungal treatment $[3,13,17]$.

Echinocandin are usually consider the first line treatment for C. glabrata infections but the burden of Echinocandin (Caspofungin) resistance is still worry some in patients with Candida infections due to C. glabrata. In our study whereas Amphotericin B considered the gold standard treatment for fungal infection and all isolates of $C$. glabrata shown susceptible to Amphotericin B and Flucytosine this finding were concord with other findings [1,9].

However certain Non albicans Candida species in the Asia Pacific region Fluconazole resistance in Candida tropicalis reported ranges from 0 to as high as $83 \%[4,5]$ while in our findings the Candida tropicalis were $10 \%$ resistant to Fluconazole, this is similar with previous finding [1].

All Candida kefyr isolates found to be susceptible to tested antifungal drugs therefore the use of routine antifungal agents like Fluconazole, Amphotericin B and all antifungal drugs that are available in this region suggested for treatment of these Candida species.

Of the increasing concern, the number of multidrug resistant isolates of Candida parapsilosis ranges 25\% of all antifungals except Flucytosine. Previous studies by worldwide are in agreement with this study $[1-3,10,16,18]$.

Candida krusei is well known recognized as a potentially MDR fungal pathogen, due to its intrinsically resistant to Fluconazole. We find out all isolates of Candida krusei were $100 \%$ sensitive to Voriconazole, and decreased susceptibilities noted to Amphotericin B. In addition this species clearly exhibits, $100 \%$ decreased susceptibility to Flucytosine (Table 4 ) were in agreement with previous study by Plaffer MA, et al. [19].

Whereas we find out more than $50 \%$ of isolates were resistant to Caspofungin an Echinocandin which is new agents to treat serious Candida infections which targets the fungal cell wall and it retains activity against isolates with resistant to azoles or polyenes. The number of resistance increasing is worrying about the therapy for Candida krusei infection and were very similar to other studies $[3,9,13,16,17,19]$.

This study highlighted only Voriconazole and Micafungin were suitable for Candida krusei treatment in this region.

Candida auris is an emerging opportunistic pathogen, first reported in 2009 as an isolate from an external ear of a patient in Japan. It identified as cause of nosocomial infection in numerous countries in East Asia, the Middle East, Africa, and Europe $[15,20,21]$. C. auris, said that almost 90 per cent of the fungal isolates found to be resistant to Fluconazole, the standard antifungal drug of choice in many countries $[10,20,21]$. According to Chowdhary, the first case of Candida auris reported in India was from 2011. Besides, the pathogen is capable of surviving on hospital paraphernalia such as mattresses, bedrails, and windowsills for long, making it possible to spread among patients [14].

In Delhi Kodameae ohmeri is also an emerging infection have been reported and were isolated from bal, sputum, urine respectively this is an agreement with previous study $[6,22]$.

\begin{abstract}
Kodameae ohmeri and Candida auris species are ubiquitous fungi causing severe disease in immunocompromised individuals and hampered by absence of accurate species identification this yeasts commonly misidentified as Candida haemulonii and Rhodotorula glutinis by routine laboratory using conventional methods. Yet correct identification up to species level characterized by Matrix-assisted laser desorption ionization-time of flight mass spectrometry (MALDI-TOF MS). Hence, it considered a more rapid diagnostic technique for identification of this rare yeast isolates (Kodameae ohmeri and Candida auris) and may help to switch effective treatment and reduce the duration of hospital stay.
\end{abstract}

Over the past two decades, several studies reported noscomial sepsis by the uncommon fungal species such Trichosporon asahii. This fungal species occasionally are part of the gastrointestinal and oral cavity and can transiently colonize the respiratory tract and skin. In our study $1.1 \%$ of Trichosporon asahii isolated from respitatory and other specimens. And this fungus was found to be sensitive to 


\section{Open Access Journal of Mycology \& Mycological Sciences}

Voriconazole and Micafungin but resistance of Amphotericin B, Caspofungin and Fluconazole were alarming, this is similar with previous finding [23-25].

In this study, we have demonstrated that the incidence of fungemia caused by Rhodotorula mucilaginosa was five $(0.6 \%)$ that is isolated from tissue and skin. However, currently saprophytic yeasts like Rhodotorula spp. are emerging pathogens and few epidemiological studies have described Rhodotorula as the aetiological agent in $0.5-2.3 \%$ cases of fungemia are in agreement with this study $[26,27]$.

\section{Conclusion}

The fungal pathogens have changed over a period with new species emerging as well as old species increasingly become more virulent, resistant to primary antifungal drugs and important to see the difference in antifungal susceptibility in different yeast species. Emergence of increasing resistance of antifungal drugs has become the concern for policy makers and urgent need of strict antifungal prescription policy in our country. Judicious selection of antifungal drugs as per yeast species recommendation by CLSI M-60 is the need of hour. We should be concern about the national emergence and awareness of this rare fungus (Kodameae ohmeri, Candida auris) as a cause of invasive infection and severe sepsis.

\section{Ethical Approval}

It is not applicable.

\section{Conflicts of interest}

There are no conflicts of interest.

\section{Acknowledgements}

We are thankful to Dr Reena Nakra, Lab director operations National Reference Laboratory, Dr Lal Path Labs, Delhi for providing us operational support and team Microbiology for technical assistance in conducting the study.

\section{References}

1. Oberoi JK, Wattal C, Goel N, Raveendran R, Datta S, et al., (2012) Non-albicans Candida species in blood stream infections in a tertiary care hospital at New Delhi, India. Indian Journal of Medical Research 136(6): 997-1003.

2. Lindberg E, Hammarstrom $\mathrm{H}$, Ataollahy N, Kondori $\mathrm{N}$ (2019) Species distribution and antifungal drug susceptibilities of yeasts isolated from the blood samples of patients with candidemia. Sci Rep 9(1): 3838.

3. Perlin DS (2015) Echinocandin resistance in Candida. Clin Infect Dis 61(S 6): 612-617.
4. Whaley SG, Berkow EL, Rybak JM, Nishimoto AT, Barker KS, et al. (2017) Azole Antifungal Resistance in Candida albicans and Emerging Non-albicans Candida Species. Front Microbiol 7: 2173.

5. Effron GG, Kontoyiannis DP, Lewis RE, Perlin DS (2008) Caspofungin-Resistant Candida tropicalis Strains Causing Breakthrough Fungemia in Patients at High Risk for Hematologic Malignancies. Antimicrob Agents Chemother 52(11): 4181-4183.

6. Tashiro A, Nei T, Sugimoto R, Watanabe A, Hagiwara J, et al. (2018) Kodamaea ohmeri fungemia in severe burn: case study and literature review. Med Mycol case Rep 22: 21-23.

7. ElMashad NBE, Abdel Aal AM, Elewa AM, Elshaer MYS (2019) Noscomial yeast infections among cancer patients in Egypt: species distribution and antifungal susceptibility profile. Jundishapur J Microbiol 12(2): e82421.

8. Kabir MA, Zulfiqar A (2013) Candida infections and their prevention. ISRN Prev Med.

9. Spampinato C, Leonardi D (2013) Candida infections, causes, targets and Resistance mechanisms: Traditional and Alternative Antifungal Agents. Biomed Res Int.

10. Mathur P, Hasan F, Singh PK, Malhotra R, Walia K, et al. (2018) Five year profile of candidaemia at an Indian trauma centre: high rates of Candida auris blood stream infections. Mycoses 6(91): 116-120.

11. Giri S, Kindo AJ (2012) A review of Candida species causing blood stream infection. Indian J Med Microbiol 30(3): 270-278.

12. Kothari A, Sagar V (2009) Epidemiology of candida bloodstream infections in a tertiary care institute in India. Indian J Med Microbiol 27(2): 171-172.

13. Berrouane YF, Herwaldt AL, Pfaller MA (1998) Trends in antifungal use and epidemiology of Nosocomial Yeast Infections in a University hospital. J Clin Microbiol 37(3): 531-537.

14. Chowdhary A, Sharma C, Meis JF (2017) Candida auris: A rapidly emerging cause of hospital acquired multidrug resistant fungal infections globally. PLoS Pathog 13(5): e1006290.

15. Ami RB, Berman J, Novikov A, Bash E, et al., (2017) Multidrug resistant Candida haemulonii and C. auris, Tel Aviv, Israel. Emerg Infect Dis 23(1): 195-203.

16. Pristov KE, Ghannoum MA (2019) Resistance of Candida 
to azoles and echinocandins worldwide. Clin Microbiol Infect 25(7): 792-798.

17. Maheshwari M, Kaur R, Chadha S (2016) Candida Species Prevalence Profile in HIV Seropositive Patients from a Major Tertiary Care Hospital in New Delhi, India. J Pathogens.

18. Moudgal V, Little T, Boikov D, Vazquez JA (2005) Multiechinocandin- and Multiazole-Resistant Candida parapsilosis Isolates Serially Obtained during Therapy for Prosthetic Valve Endocarditis. Antimicrobial Agents Chemotherapy 49(2): 767-769.

19. Pfaller MA, Diekema DJ, Gibbs DL, Newell VA, Nagy E, et al. (2008) Candida krusei, a multidrug resistant opportunistic Fungal Pathogen: Geographic and Temporal trends from the ARTEMIS DISK Antifungal Surveillance Program, 2001 to 2005. J Clinical Microbiol 46(2): 515-521.

20. Walia K, Chowdhary A, Ohri VC, Chakrabarti A (2017) Multidrug resistant Candida auris: Need for alert among microbiologists. Indian J Med Microbiol 35(3): 436.

21. Spivak ES, Hanson KE (2018) Candida auris: An Emerging Fungal Pathogen. J Clin Microbiol 56(2): e01588-17.
22. Lefevre B, Cadelis G, Gallois JC, Gandon F, Nicolas M, et al. (2019) A case report of fungemia due to Kodamaea ohmeri. BMC infectious diseases 19: 570.

23. Basu S, Tilak R, Kumar A (2015) Multidrug-resistant Trichosporon: an unusual fungal sepsis in preterm neonates. Pathog Glob health 109(4): 202-206.

24. Barbara DA, Gray WP, Phillipe D, Jeff F, Wayne PA, et al. (2017) Performance standards for Antifungal Susceptibility Testing of yeasts. $1^{\text {st }}$ (Edn.), CLSI supplement M60, pp: 1-12.

25. Uppal B, Panda PS, Kishor S, Sharma S, Farooqui FH (2016) Speciation of Candida isolates obtained from diarrheal stool. Egypt J Intern Med 28(2): 66-70.

26. Capoor MR, Aggarwal S, Raghvan C, Gupta DK, Jain AK, et al. (2014) Clinical and microbiological characteristics of Rhodotorula mucilaginosa infections in a tertiary care facility. Indian J Med Microbiol 32(3): 304-319.

27. De Almeida GM, Costa SF, Melhem M, Motta AL, Szeszs MW, et al. (2008) Rhodotorula spp. isolated from blood cultures: Clinical and microbiological aspects. Med Mycol 46(6): 547-556. 